\title{
Cabergoline is an effective treatment for clinically non-functioning pituitary adenomas
}

Greenman $\mathrm{Y}^{1,5}$, Cooper $\mathrm{O}^{6}$, Yaish ${ }^{1}$, Robenshtok $\mathrm{E}^{4,5}$, Sagiv $\mathrm{N}^{1}$, Jonash $\mathrm{KT}^{3,5}$, Mallick $\mathrm{J}^{7}$, Gertych $\mathrm{A}^{7}$, Shimon 14,5, Ram Z2,5, Melmed S ${ }^{6}$, Stern $\mathrm{N}^{1,3}$

${ }^{1}$ Institute of Endocrinology and Metabolism, ${ }^{2}$ Department of Neurosurgery, and ${ }^{3}$ Neuroradiology Unit, Tel Aviv Sourasky Medical

Center; ${ }^{4}$ Institute of Endocrinology and Metabolism, Rabin Medical Center; ${ }^{5}$ Sackler Faculty of Medicine, Tel Aviv University.

${ }^{6}$ Pituitary Center, and ${ }^{7}$ Pathology Department, Cedars Sinai Medical Center.

\section{OBJECTIVES}

- To evaluate the role of DA therapy in patients with NFPA residual tumors after surgery

- To examine whether there is a correlation between response to DA treatment and D2R tumors expression

- To evaluate predictive factors associated with tumors response

\section{METHODS}

- Retrospective analysis of prospectively collected data was conducted at two pituitary referral centers with different standard practices for post-operative management of NFPA: DA therapy or conservative follow up.

- Patients were treated (cabergoline $2 \mathrm{mg} /$ week) upon detection of residual tumor on postoperative MRI (preventive treatment- $\mathrm{PT}$ - group, $\mathrm{N}=55$ ), or when tumor growth was detected during follow-up (remedial treatment -RT-group, $\mathrm{N}=24$ ). The control group received no medication and comprised 60 patients.

- Dopamine receptor 2 (D2R) expression was examined by immunohistochemistry,

- D2R long and short isoform mRNA expression was measured by quantitative RTPCR.

\begin{tabular}{|c|c|c|c|c|}
\hline & \multicolumn{2}{|c|}{$\begin{array}{l}\text { Control } \\
\text { group (60) }\end{array}$} & $\begin{array}{l}\text { Treatment } \\
\text { group (79) }\end{array}$ & p value \\
\hline Sex F/M & \multicolumn{2}{|c|}{$21 / 39$} & $33 / 46$ & NS \\
\hline Age & \multicolumn{2}{|c|}{$57.3 \pm 14$} & $57.8 \pm 13$ & NS \\
\hline $\begin{array}{l}\text { Maximal diameter } \\
\text { (pre-op) }\end{array}$ & \multicolumn{2}{|c|}{$26.2 \pm 10.9$} & $28.5 \pm 11.5$ & NS \\
\hline Invasiveness & \multicolumn{2}{|l|}{$58.3 \%$} & $57 \%$ & NS \\
\hline Visual field defects & \multicolumn{2}{|l|}{$58.3 \%$} & $52 \%$ & NS \\
\hline $\begin{array}{l}\text { Macroadenoma } \\
\text { (post-op) }\end{array}$ & \multicolumn{2}{|l|}{$63.6 \%$} & $84 \%$ & 0.014 \\
\hline High prolactin & \multicolumn{2}{|l|}{$31.8 \%$} & $34.4 \%$ & NS \\
\hline \multirow{2}{*}{ Follow up $(y)$} & \multicolumn{2}{|l|}{$6.3 \pm 5.2$} & $8.8 \pm 6.5$ & 0.018 \\
\hline & Control & \multicolumn{2}{|c|}{$\begin{array}{l}\text { Remedial } \\
\text { treatment }\end{array}$} & $\begin{array}{l}\text { Preventive } \\
\text { treatment }\end{array}$ \\
\hline Shrinkage & \multicolumn{3}{|c|}{$29.2 \%$} & $38.2 \%$ \\
\hline Stable & \multicolumn{3}{|l|}{$46.7 \%$} & $49.1 \%$ \\
\hline Growth & \multicolumn{3}{|l|}{$53.3 \%$} & $12.7 \%$ \\
\hline $\begin{array}{l}\text { Tumor control } \\
\text { (shrinkage + } \\
\text { stabilization) }\end{array}$ & \multicolumn{3}{|c|}{$46.7 \% \quad 58.3 \%$} & $87.3 \%$ \\
\hline
\end{tabular}

\section{No association between D2R expression and response to treatment}
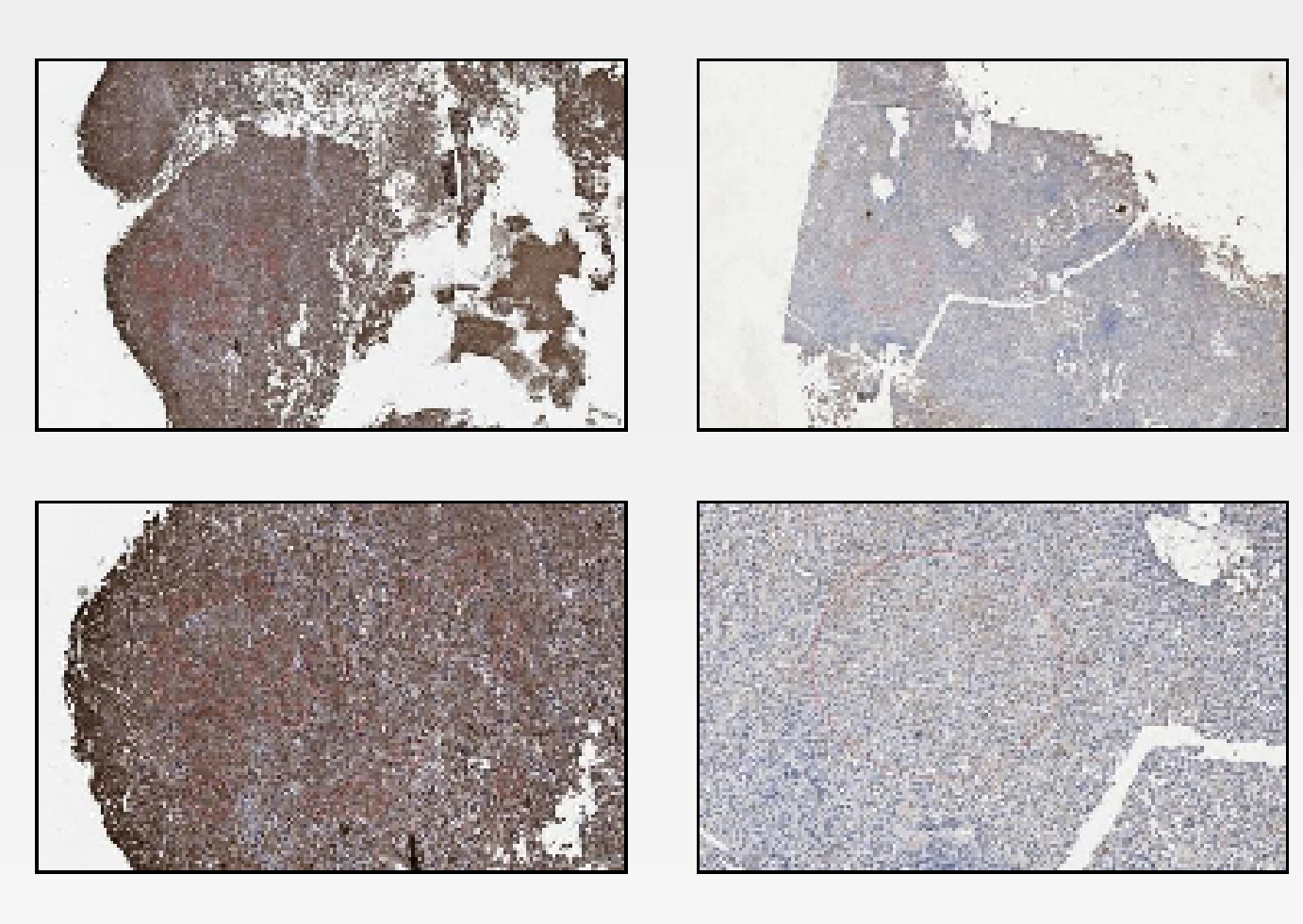

Immunostaining for D2R

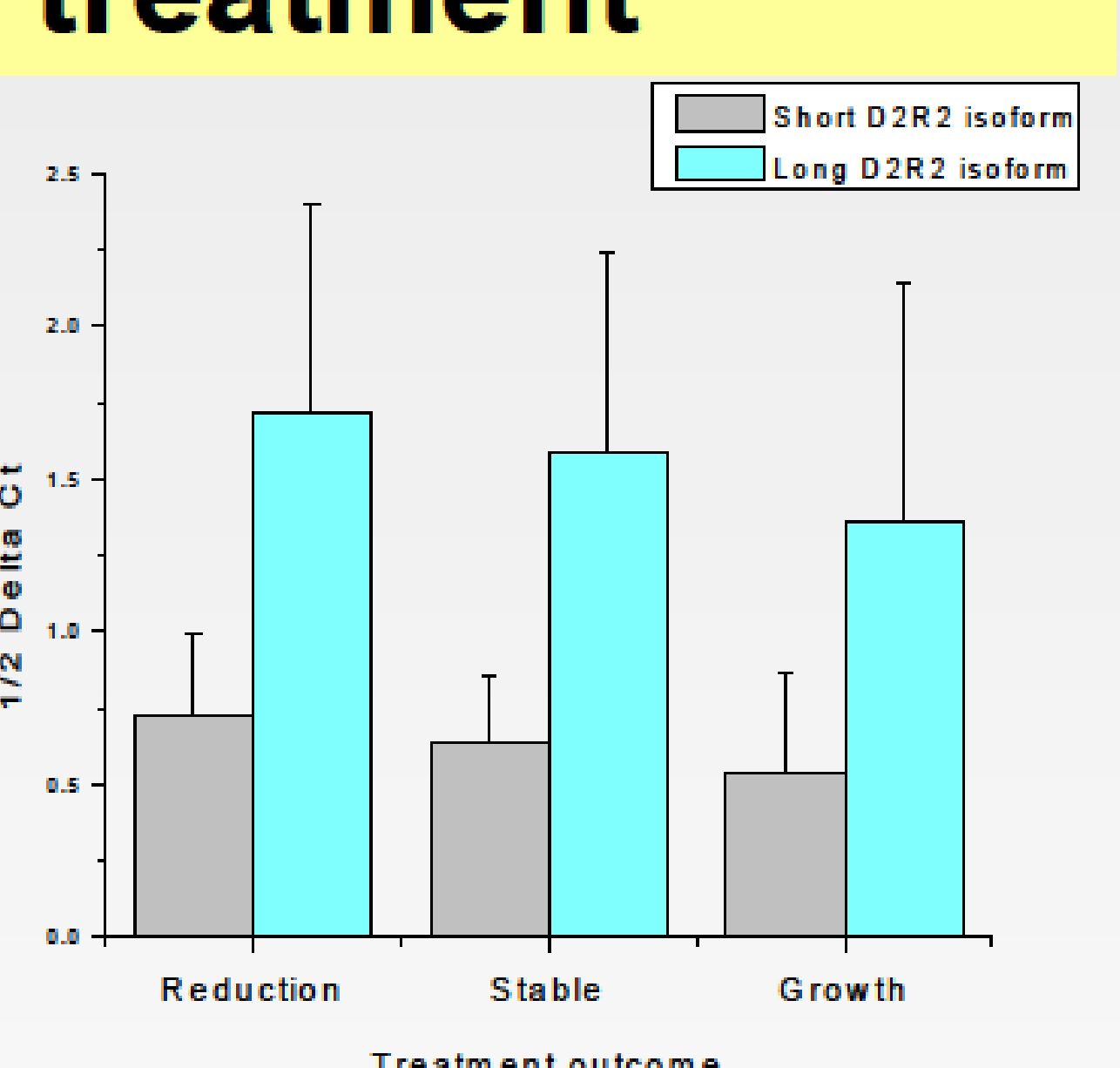

$\mathrm{D} 2 \mathrm{R}$ isoforms $\mathrm{m}$ RNA

\section{Clinical Implications}

- Preventive post-op DA therapy achieved tumor control in $87.3 \%$ of patients with residual tumors

- Shrinkage or stabilization was achieved in $58.4 \%$ of the enlarging tumors in the RT group

- $41.7 \%$ of patients in the control group required additional surgery and/or radiotherapy as compared to $20.2 \%$ of the combined treatment groups $(p=0.0084)$.

\section{RESULTS}

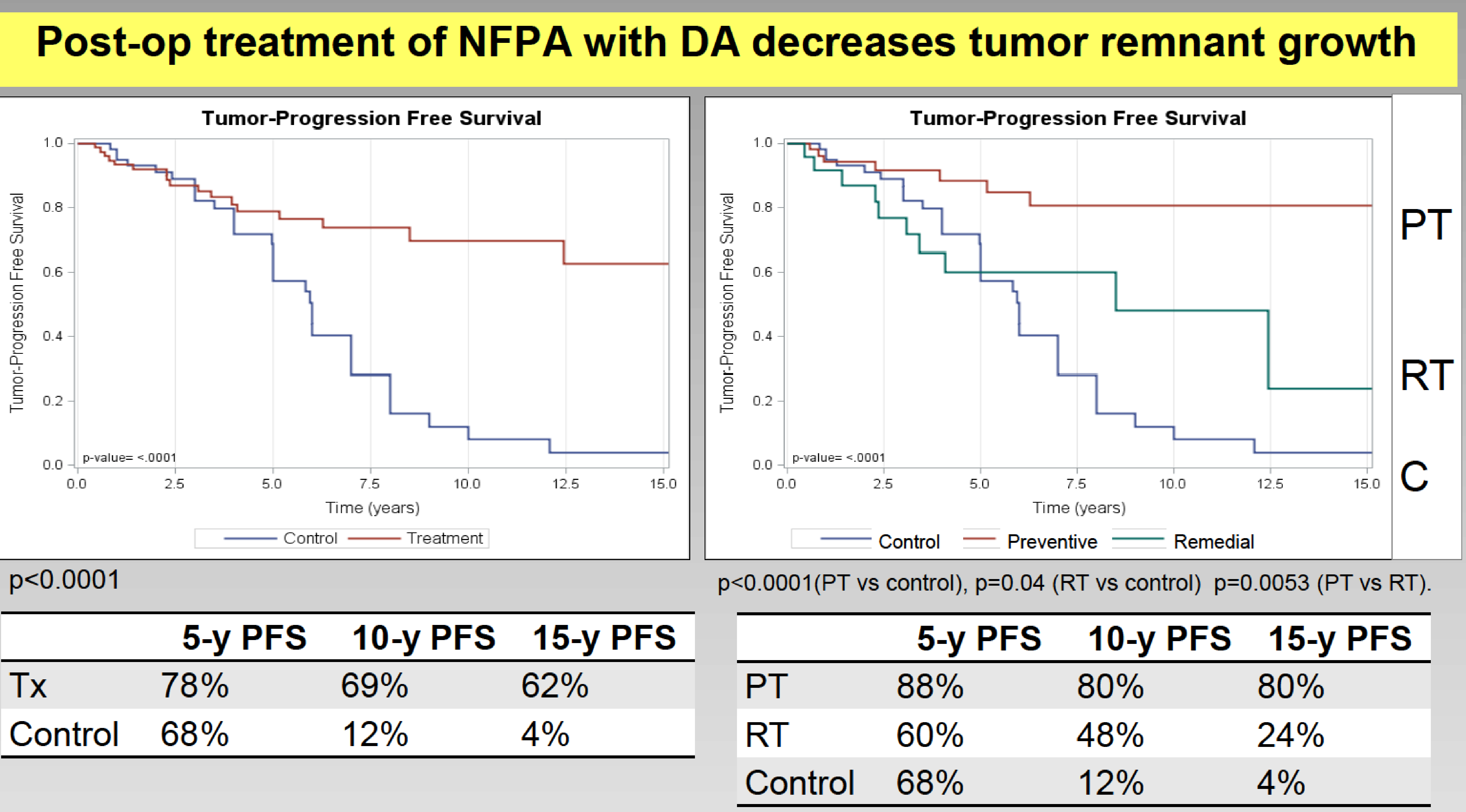

Multivariate analysis for tumor progression

\begin{tabular}{|c|c|c|c|c|c|}
\hline & & $\mathrm{X}^{2}$ & $p$ & HR & $95 \% \mathrm{Cl}$ \\
\hline $\begin{array}{l}\text { Medical } \\
\text { Center }\end{array}$ & Treatment & 9.95 & 0.0016 & 0.32 & $0.16-0.65$ \\
\hline $\begin{array}{l}\text { Post op } \\
\text { micro/ } \\
\text { macro }\end{array}$ & Macro & 0.06 & 0.8 & 0.91 & $0.43-1.89$ \\
\hline Sex & Male & 5.15 & 0.023 & 2.29 & $1.12-4.68$ \\
\hline Age & & 8.61 & 0.003 & 0.96 & $0.94-0.98$ \\
\hline
\end{tabular}

\section{CONCLUSIONS}

Dopamine agonist therapy is associated with decreased prevalence of residual tumor enlargement in patients with NFPA, particularly when treatment is instituted prophylactically after surgical resection 